\title{
Local Liquid Holdups and Hysteresis in a 2-D Packed Bed Using X-ray Radiography
}

\author{
M. G. Basavaraj, G. S. Gupta, and K. Naveen \\ Dept. of Metallurgy, Indian Institute of Science, Bangalore 560 012, India
}

\begin{abstract}
V. Rudolph
Division of Chemical Engineering, School of Engineering, University of Queensland, St. Lucia, Queensland 4072, Australia

R. Bali

Dept. of Metallurgical and Materials Engineering, National Institute of Technology Karnataka, Surathkal 575 025, India
\end{abstract}

DOI 10.1002/aic.10481

Published online May 23, 2005 in Wiley InterScience (www.interscience.wiley.com).

\begin{abstract}
An X-ray visualization technique has been used for the quantitative determination of local liquid holdups distribution and liquid holdup hysteresis in a nonwetting twodimensional (2-D) packed bed. A medical diagnostic X-ray unit has been used to image the local holdups in a 2-D cold model having a random packing of expanded polystyrene beads. An aqueous barium chloride solution was used as a fluid to achieve good contrast on X-ray images. To quantify the local liquid holdup, a simple calibration technique has been developed that can be used for most of the radiological methods such as gamma ray and neutron radiography. The global value of total liquid holdup, obtained by X-ray method, has been compared with two conventional methods: drainage and tracer response. The X-ray technique, after validation, has been used to visualize and quantify the liquid hysteresis phenomena in a packed bed. The liquid flows in preferred paths or channels that carry droplets/rivulets of increasing size and number as the liquid flow rate is increased. When the flow is reduced, these paths are retained and the higher liquid holdup that persists in these regions leads to the holdup hysteresis effect. Holdup in some regions of the packed bed may be an order of magnitude higher than average at a particular flow rate.
\end{abstract}

Keywords: packed bed, x-ray, holdups, liquid hysteresis, nonwetting flow

\section{Introduction}

Research on hydrodynamics in porous media has been an active area for many decades, having widespread application in

M. G. Basavaraj, a graduate student at the Dept. of Metallurgy, Indian Institute of Science, Bangalore, India, is currently at the Dept. of Chemical Engineering, K.U. Leuven, Leuven B-3001, Belgium.

R. Bali was a summer student at the Dept. of Metallurgy, Indian Institute of Science, Bangalore, India.

Correspondence concerning this article should be addressed to G. S. Gupta at govind@met.iisc.ernet.in many disciplinary areas such as chemical, civil, and metallurgical engineering. Continuing efforts have been made to understand the complex flow phenomena through packed beds such as liquid hysteresis. Currently, the focus is on the estimation of the local parameter variation at the microscopic scale because this information is directly related to column performance. The local variation of gas, liquid, or solid holdup in a packed bed provides not only a better understanding of these systems, thus permitting better design, but also improved numerical models. ${ }^{1,2}$

The conventional methods to measure the liquid holdups in packed beds, both static and dynamic, are drainage and tracer 
response. These are the well-accepted methods that have been used by many researchers for holdup estimation. ${ }^{3-9}$ They provide the overall or global values of the static and dynamic liquid holdups but are unable to give local holdups. Also, these methods have many drawbacks, ${ }^{3,10}$ contributing toward the uncertainties in the measured values. Therefore, to attain more accurate results and the local value of liquid holdups in porous media many researchers have used visualization techniques such as neutron ${ }^{11}$ and X-ray radiography, ${ }^{12,13}$ computed tomography, ${ }^{14}$ gamma-ray tomography, ${ }^{10}$ and nuclear magnetic resonance. ${ }^{15}$ These techniques successfully provide quantification of flow parameters in porous media. Some of these have already been used for the liquid/solid holdup estimation in packed beds. ${ }^{10,14} \mathrm{X}$-ray visualization techniques have been used widely because of their relatively easy availability and cost effectiveness. Computer-assisted tomography ${ }^{12}$ has been used to qualitatively study the liquid distribution in trickle beds. In other studies, ${ }^{10,14}$ the quantitative analysis of local liquid distribution in packed beds has been done. Gamma-ray tomography ${ }^{10}$ has been used to quantify liquid holdup distribution in a packed bed. Radiological study of liquid holdup and flow distribution in packed gas-absorption columns has also been reported. ${ }^{16}$ Recently, the saturation concentration field in a two-dimensional (2-D) thin-slab porous system using X-ray absorption technique has been studied by a few investigators. ${ }^{17,18}$ Most of the above investigators, who have studied the holdup/concentration using X-ray radiography, have ignored the errors associated with the polychromatic nature of X-ray and image-processing operations.

In this paper, we present a simple technique to measure the local liquid holdups in a packed column that largely overcomes these two problems. Using this technique, both static and dynamic local liquid holdups have been measured quantitatively. Values of the global liquid holdups (static and dynamic), obtained from the X-ray technique, have been compared with the values obtained by two conventional methods: drainage and tracer dynamics. After validation, this X-ray method has been used to study the liquid hysteresis phenomena.

Until now, the hydrodynamic behavior and physical interpretation of trickling beds have mostly relied on empirical correlations and the global observations made in the beds, although this averaging approach obscures localized behavior and loses many small-scale details that actually dominate system outcomes. Using visualization techniques many important observations on the flow behavior of liquid in trickling bed can be made. One of the less-understood phenomena in trickling beds is liquid holdup hysteresis, which has consequently attracted the attention of many researchers. ${ }^{19-23}$ However, results obtained often conflict. For example, Christensen et al. ${ }^{20}$ show larger liquid holdup with increasing liquid flow compared with decreasing flow, whereas Levec et al. ${ }^{22}$ show the reverse trend. Some of the authors ${ }^{19,20,22,24}$ have also reported that liquid holdup depends on the bed history. Based on our visualized experimental results of packed bed in various conditions, a clearer picture of liquid hysteresis phenomena from qualitative and quantitative perspective is presented here. Results are presented that relate to liquid hysteresis phenomena at both local and global scales. Also, it is shown that both static and dynamic liquid holdups contribute toward the liquid hysteresis.

\section{X-ray Absorption Principle and Calibration Theory}

$\mathrm{X}$-ray absorption is a nondestructive means of producing 2-D images that reveal the interior of an opaque object. These images provide a point array with each point assigned a gray level between 0 and 255 according to the transmitted X-ray intensity. The gray-scale intensity data from these images are related to X-ray attenuation by the specimen according to the Beer-Lambert law, which is described below.

Experiments have shown ${ }^{25,26}$ that the fractional decrease in the intensity of an X-ray beam passing through a specimen is related to its thickness, mass absorption coefficient, and density and is represented mathematically as

$$
I=I_{0} e^{-(\mu / \rho) \rho x}
$$

where $I_{0}$ and $I$ are the intensities of incident and transmitted beams, respectively; $(\mu / \rho)$ is the mass absorption coefficient for the material $\left(\mathrm{m}^{2} / \mathrm{kg}\right) ; \rho$ is the density of the material $\left(\mathrm{kg} / \mathrm{m}^{3}\right)$; and $x$ is the path length of the X-ray beam $(\mathrm{m})$.

The mass absorption coefficient is a function of the wavelength and atomic number of the absorbing material. Therefore, absorption of X-rays is an exponential function of the atomic number and is much greater for the heavy atoms such as iodine, barium, and bromine than for the lighter ones such as carbon, hydrogen, and oxygen. ${ }^{13}$

All the medical and industrial X-ray units are polychromatic in nature. Stenoscop, used during the present experiment, also emits polychromatic X-rays. Therefore, the absorption of polychromatic X-rays by a composite sample (having more than one chemical species) can be related to incident and transmitted intensities as ${ }^{27}$

$$
\begin{aligned}
I= & I_{0} \exp \left\langle-\left\{\left[w_{1}^{*}(\mu / \rho)_{1}+w_{2}^{*}(\mu / \rho)_{2}+w_{3}^{*}(\mu / \rho)_{3}+\cdots\right.\right.\right. \\
& \left.+w_{n}^{*}(\mu / \rho)_{n}\right]_{\lambda_{1}}+\left[w_{1}^{*}(\mu / \rho)_{1}+w_{2}^{*}(\mu / \rho)_{2}+w_{3}^{*}(\mu / \rho)_{3}+\cdots\right. \\
& \left.+w_{n}^{*}(\mu / \rho)_{n}\right]_{\lambda_{2}}+\left[w_{1}^{*}(\mu / \rho)_{1}+w_{2}^{*}(\mu / \rho)_{2}+w_{3}^{*}(\mu / \rho)_{3}+\cdots\right. \\
& \left.+w_{n}^{*}(\mu / \rho)_{n}\right]_{\lambda_{3}}+\cdots+\left[w_{1}^{*}(\mu / \rho)_{1}+w_{2}^{*}(\mu / \rho)_{2}+w_{3}^{*}(\mu / \rho)_{3}\right. \\
& \left.\left.\left.+\cdots+w_{n}^{*}(\mu / \rho)_{n}\right]_{\lambda_{n}}\right\} \rho x\right\rangle
\end{aligned}
$$

where the subscripts $1,2,3, \ldots, n$ indicate the chemical species present in the sample; $w$ is the respective weight fraction; $\mu / \rho$ is the mass absorption coefficient of the respective chemical species; and $\lambda_{1}, \lambda_{2}, \lambda_{3} \cdots$ represent wavelength distribution of polychromatic X-rays; $I$ and $I_{0}$ are the intensities of transmitted and incident X-ray beams, respectively.

When using polychromatic X-rays, the calculation of mass absorption coefficient (of each species), which relates transmitted and incident intensity to path length, is not only very complicated but also less accurate. Published mass absorption coefficients are not yet accurate enough at most wavelengths. The main uncertainty is knowing the wavelength and corresponding X-ray intensities. ${ }^{27}$ Moreover, the mass absorption coefficient of many of the chemical species is not yet known. Without knowledge of these parameters, the beam-hardening effect may be introduced, which further increases the complexity in quantitatively analyzing the images. Therefore, a simple calibration technique, discussed below, has been developed 


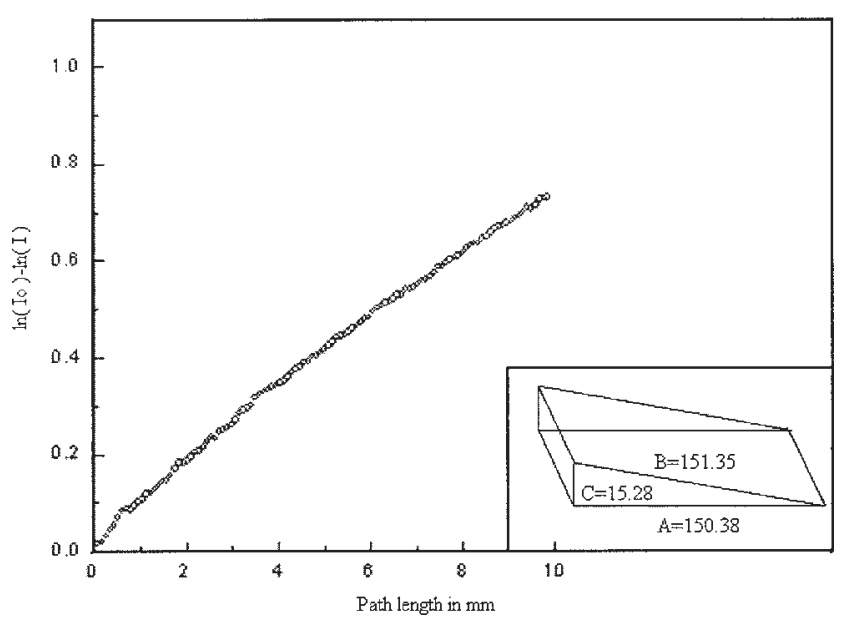

Figure 1. Calibration graph for local/total liquid holdup measurement.

that addresses and overcomes all the above-mentioned difficulties, to a reasonable approximation.

Because the aqueous barium chloride solution, used in the present study as dopant, contains more than one chemical species, the Beer-Lambert law (Eq. 1) can be applied ${ }^{25-27}$ in which the mass absorption coefficient can be expressed as

$$
\frac{\mu}{\rho}=\left[w_{\text {water }}\left(\frac{\mu}{\rho}\right)_{\text {water }}+W_{\mathrm{BaCl}_{2}}\left(\frac{\mu}{\rho}\right)_{\mathrm{BaCl}_{2}}\right] \lambda_{i} \quad(i=1,2, \ldots, n)
$$

where $\lambda_{i}$ represents the wavelength distribution of polychromatic X-rays and $w$ is the weight fraction. To overcome unavailability of wavelength distribution, we have used the same operating conditions for the calibration and liquid holdup and hysteresis experiments. It is assumed that this distribution remains identical as long as the operating conditions of the $\mathrm{X}$-ray unit are the same. In Eq. $1 x$ is the path length of X-ray beams through which it gets absorbed. Also, it can be said that $x$ is the thickness of the liquid through which the $\mathrm{X}$-ray passes.

We consider first a packed bed made of a particulate material (beads) through which liquid is flowing. Scans of this system in various conditions using $\mathrm{X}$-rays result in the expressions that follow. Assuming negligible absorption of X-rays by air then for an empty column the Beer-Lambert law gives

$$
\ln \left(I_{1} / I_{0}\right)=-\mu_{1} 2 x_{1} \quad \text { (for empty column) }
$$

where $I_{1}$ and $I_{0}$ are the incident and transmitted intensities of $\mathrm{X}$-ray beams, respectively. Similarly,

$$
\ln \left(I_{2} / I_{1}\right)=-\mu_{2} x_{2} \quad \text { (for beads) }
$$

and

$$
\ln \left(I_{3} / I_{2}\right)=-\mu_{3} x_{3} \quad \text { (for liquid) }
$$

where $\mu_{1}, \mu_{2}$, and $\mu_{3}$ are absorption coefficient of column's material, beads, and liquid, respectively; $x_{1}, x_{2}$, and $x_{3}$ are the path lengths of the X-ray through the column (twice), beads, and liquid, respectively. The absorption coefficient is different from the mass absorption coefficient. Using the above equations, $I_{1}$ and $I_{2}$ can be eliminated and the resulting equation can be written as

$$
I_{3}=I=I_{0} e^{-\left(\mu_{1} 2 x_{1}+\mu_{2} x_{2}+\mu_{3} x_{3}\right)}
$$

or

$$
I_{3}=I_{0}^{\prime} e^{-\left(\mu_{3} x_{3}\right)}
$$

where

$$
I_{0}^{\prime}=I_{0} e^{-\left(\mu_{1} 2 x_{1}+\mu_{2} x_{2}\right)}
$$

and $x_{1}$ and $x_{2}$ are constant throughout the experiment. However, the liquid thickness $x_{3}$ will not be constant throughout the packed bed. Therefore, from the X-ray image of the column filled with beads, one can obtain the gray-scale values that, in principle, will be constant in all the experiments. Therefore, $I_{0}^{\prime}$ in terms of gray level is known. If liquid is flowing through the packing, then $I_{3}$ is required for the various path lengths $x_{3}$ (thickness) of the liquid. Therefore, according to the theory (Eq. 8), a plot of $\ln I_{0}^{\prime}-\ln I_{3}$ against path length $\left(x_{3}\right)$ will give a straight line, with the slope providing the value of absorption coefficient of the composite substance.

In practice, it has been observed by many researchers ${ }^{28-30}$ that a curve between $\ln I_{0}^{\prime}-\ln I_{3}$ against path length deviates from linearity after some path length, a phenomenon that is explained by the beam-hardening effect. However, this effect can be minimized by adopting proper methods such as hardware filtering, ${ }^{31}$ linearization method, ${ }^{32}$ and dual energy. ${ }^{31,33}$ In the present study hardware filtering ( $3 \mathrm{~mm} \mathrm{Al} \mathrm{equivalent)} \mathrm{and}$ low concentration solution have been used to minimize the beam-hardening effect. Preparation of the calibration graph is discussed below.

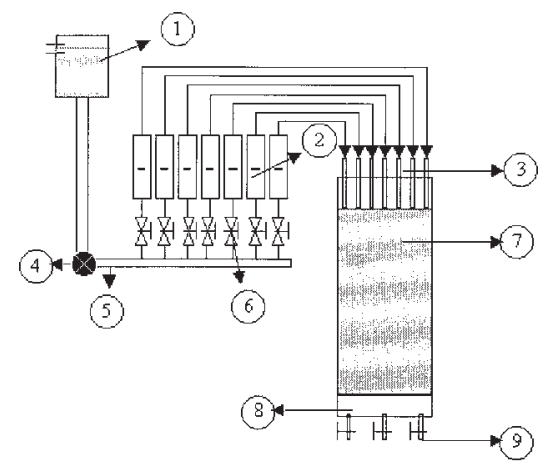

Figure 2. Experimental arrangements for local holdup measurement.

1: Constant head tank; 2: Rotameters; 3 : Packed bed inlet; 4: Main flow control valve; 5: Main flow line; 6 : Control valves for rotameter; 7: Packed bed; 8: Liquid collector box; 9: Liquid drain. 


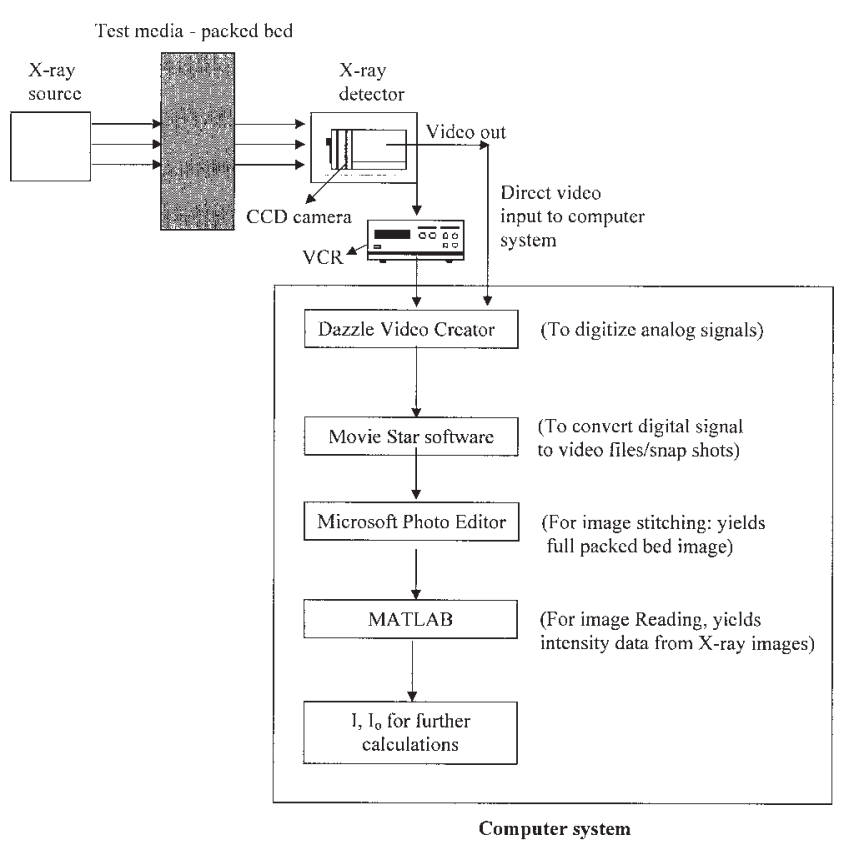

Figure 3. X-ray absorption imaging system.

\section{Calibration Graph}

The holdup calibration graph relates the amount or volume of liquid trapped in the bed under dynamic and static conditions with the intensity in the X-ray images of a packed bed arising from change in path length.

The calibration is done experimentally using a prism made from Perspex ${ }^{\circledR}$ (trade name in the United Kingdom for polymethyl methacrylate), which permits a different X-ray path length through barium chloride solution to be conveniently and accurately implemented. The arrangement is shown in Figure 1. Because the prism is made of Perspex ${ }^{\circledR}$, the same material and thickness as the packed bed, the experiment directly calibrates the X-ray intensity and the amount of barium chloride (Figure 1). The parameters, which can change the nature of the calibration curve, are the concentration of barium chloride and the current and voltage at which the X-ray machine is used. Consequently, calibration is done using a barium chloride solution concentration equivalent to that used in the column holdup experiments, and using the same operating current and voltages. A fresh calibration graph was prepared for each of the holdup experiments. More details about the preparation of calibration graph in various other conditions have been described elsewhere. ${ }^{34}$

\section{Experimental Plan Setup}

A schematic diagram of a 2-D apparatus used in the experiments is shown in Figure 2. The apparatus, made from a Perspex $^{\circledR}$ sheet $(10$-mm-thick), had dimensions of $750 \times$ $170 \times 60 \mathrm{~mm}$ [height $\times$ width $\times$ thickness (depth)]. A stainless steel screen having a $2-\mathrm{mm}$ aperture at the bottom supported the bed materials. Below the stainless screen a liquid collecting box was attached to collect the liquid.

For X-ray visualization, a low-concentration solution of aqueous barium chloride was used. The solution was supplied from a constant overhead tank to the rotameters as shown in Figure 2. Each rotameter had a maximum flow rate of 0.1 liters per minute $(\mathrm{lpm})$. The rotameters were equally spaced at 24-mm intervals. Liquid was collected in separate drainage boxes at the bottom of the packed bed.

\section{Materials}

Spherical expanded polystyrene beads (diameter: $3.77 \pm 0.5$ $\mathrm{mm}$ ) were used as the packing material. These particles are not wetted by aqueous barium chloride solution. Expanded polystyrene was chosen as the packing material because it is made of low atomic number elements and has a very low density of about $25 \mathrm{~kg} / \mathrm{m}^{3}$ and thus absorbs almost no X-rays, thus allowing a good contrast between the liquid and packing material. The liquid was barium chloride in water solution, having a concentration of $0.096 \mathrm{~g} \mathrm{BaCl}_{2} / \mathrm{mL}$ of water and a solution density of $1120 \mathrm{~kg} / \mathrm{m}^{3}$.

\section{$X$-ray machine and absorption imaging system}

Stenoscop 9000 is a mobile medical X-ray unit equipped with a $\mathrm{C}$-arm, on which an image intensifier and X-ray source are mounted. Stenoscop provides flexible movements of the $\mathrm{X}$-ray source and detector that make it easy to obtain required views. The distance between the X-ray source and the image intensifier is approximately $706 \mathrm{~mm}$ and the arc depth is 584 $\mathrm{mm}$ and both are constant. The X-ray system enables operation in one of several modes: standard radiography, high-resolution fluoroscopy, pulsed fluoroscopy, and standard fluoroscopy. Up to $50 \mathrm{~min}$ of continuous X-ray emission in the fluoroscopy mode allowed collection of the high-quality, distortion-free images. In the fluoroscopy mode, the unit can be used at various combinations of voltage (ranging from 40 to $110 \mathrm{kV}$ ) and current (ranging from 0.1 to $6 \mathrm{~mA}$ ). The unit has dual focus, small $(0.5 \mathrm{~mm})$ and large $(1.8 \mathrm{~mm})$, fixed anode (model HD281) X-ray tube with mask collimators. It has 3-mm Al equivalent filtering. The unit can be operated either in automatic brightness control (ABC) or manual mode. This unit was used in standard fluoroscopy and manual mode during all the experiments. The Stenoscop has a $22-\mathrm{cm}$ image intensifier, equipped with a Sony charged coupled device (CCD) camera with high signal-to-noise ratio to achieve an excellent quality of images. The image intensifier has a maximum resolution of $58 \mathrm{lp} / \mathrm{cm}$ and contrast ratio $21: 1$. The CCD camera gives $752 \times$ 582 pixel sensor matrix with 525/625 lines scanning at 50/60 $\mathrm{Hz}$.

The X-ray absorption imaging system is shown schematically in Figure 3. X-rays emitted from the source are made to pass through the test sample by putting the test rig in between the $\mathrm{C}$-arm (that is, between the $\mathrm{X}$-ray source and the image intensifier). The transmitted X-ray intensity is a function of the contents of the test sample integrated over its thickness. The intensity is converted into digital signals through the CCD camera and is recorded onto a video cassette using a videocassette recorder. The movie thus recorded is digitized into snapshots/frames using Dazzle hardware and Movie Star software.

These snapshots, which are the still images of the test sample, can be analyzed to explore the intensity variations occurring in the test sample. The intensity of the snapshots was measured using the IMREAD function of MATLAB software. 
To obtain the full image of the bed, ten snapshots [each having the dimensions of $5 \times 17 \mathrm{~cm}$ (height $\times$ width)] of the bed were joined together manually. A scale was placed adjacent to the bed when it was being imaged by X-rays during the experiment, which facilitates the joining process of the images accurately and ensures pixel continuity. Fifty frames of each section were averaged.

\section{Experimental Procedure Liquid holdup}

Figure 2 shows a schematic of the experimental setup. All the experiments were done under dry bed conditions. The dry apparatus was filled up with dry expanded polystyrene beads to a height of $50 \mathrm{~cm}$. Packing was random. The X-ray unit was switched on. The unit was set to standard fluoroscopy and manual modes. Operating conditions of the X-ray unit were set to a voltage of $45 \mathrm{kV}$ and current of $0.5 \mathrm{~mA}$. These parameters were selected because they give a good quality image at a good level of detail. The X-ray unit was left on under these conditions for about $15 \mathrm{~min}$ so that it would stabilize. The bed was scanned from top to bottom to get the full X-ray image of the bed. The frames/movie, corresponding to the empty bed + beads, was thus recorded onto the videocassette. The video recorder and X-ray emission were turned off. A solution of barium chloride in deionized distilled water (concentration $0.096 \mathrm{~g} \mathrm{BaCl}_{2} / \mathrm{mL}$ ) was introduced from the top of the bed through seven rotameters at a desired flow rate. The flow rate was monitored regularly. This condition was maintained for 30 min to reach the steady state. The video recorder and X-ray emission were switched on again. X-ray of the bed was taken again as described above. The video recorder and X-ray emission were switched off. The liquid flow through rotameters at the top of the bed was stopped and, simultaneously, collection of the liquid at the bottom of the bed was started. The collection of liquid was continued for $45 \mathrm{~min}$ to ensure that the entire dynamic liquid holdup has drained. The video recorder and $\mathrm{X}$-ray were switched on once again and images of the bed in this condition were recorded as described above. To determine the static holdup by a conventional (drainage) method, the bed was washed thoroughly with a known amount of deionized distilled water and the washed liquid was collected for $45 \mathrm{~min}$. Static holdup can be calculated using the mass balance approach after analyzing the tracer concentration in the washed liquid. ${ }^{35}$ At the end of each experiment, the Perspex ${ }^{\circledR}$ column and beads were washed thoroughly and then dried before starting another experiment.

To determine the total liquid holdup using the tracer technique, the same experimental setup was used as for the X-ray experiments. Deionized distilled water was introduced into the bed through all seven rotameters at $0.025 \mathrm{lpm}$ flow rate (that is, total liquid flow rate through the bed was $0.175 \mathrm{lpm}$ ). The bed was left in this condition for about $30 \mathrm{~min}$ to reach steady state. An aqueous $\mathrm{BaCl}_{2}$ solution of $0.096 \mathrm{~g} \mathrm{BaCl}_{2} / \mathrm{mL}$ of water concentration was used as a tracer. A $0.025 \mathrm{lpm}$ step input of barium chloride solution was introduced into the bed through the center inlet point at time $t=0$. Immediately a stopwatch was started and for various time intervals liquid was collected continuously at the bottom of the packed bed in small beakers while regularly monitoring the solution concentration using a conductivity probe. A conductivity meter (304 type) and a

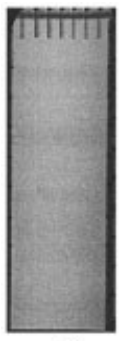

a)

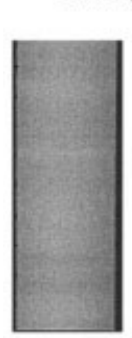

a)

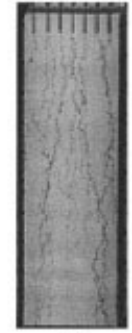

b)

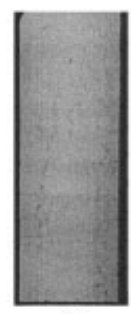

c)

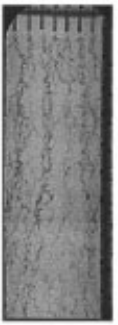

b)

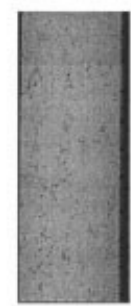

c)
Total liquid flow rate $-0.35 \mathrm{lpm}$

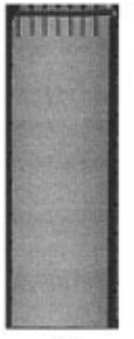

a)

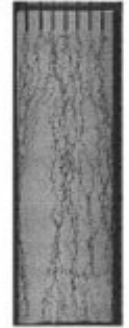

b)

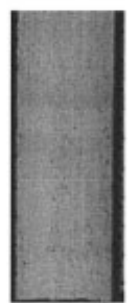

c)
Total liquid flow rate $-0.49 \mathrm{lpm}$

Figure 4. X-ray images of bed in various conditions.

(a) Dry bed; (b) liquid flow; (c) static liquid.

glass dip conductivity cell (supplied by Systronics Ltd., India) were used for this purpose. Liquid was continuously stirred in the beakers for uniformity. The collection of liquid was continued until the concentration became constant. These conductivity values were converted to respective concentration data that can be used to calculate the total liquid holdup. ${ }^{35,36}$

Tracer response and X-ray experiments were done for three (total) liquid flow rates of $0.175,0.35$, and $0.49 \mathrm{lpm}$. All the experiments were repeated.

\section{Liquid hysteresis}

For liquid hysteresis experiments the same bed, tracer, and packing material were used as in the liquid holdup experiments. The tracer was introduced at the top of the bed through a series of seven rotameters. A flow rate of $0.02 \mathrm{lpm}$ was maintained in all the rotameters. The equipment was left in this position for $15 \mathrm{~min}$ to reach the steady state. An X-ray image of the bed with steady tracer flow was captured. After finishing the X-ray scanning of the bed, the liquid flow rate was increased to $0.04 \mathrm{lpm}$ through each rotameter. The above-mentioned procedure was repeated again. Similarly, the X-ray scanning of the bed was done for 0.06 and $0.08 \mathrm{lpm}$ flow rates 


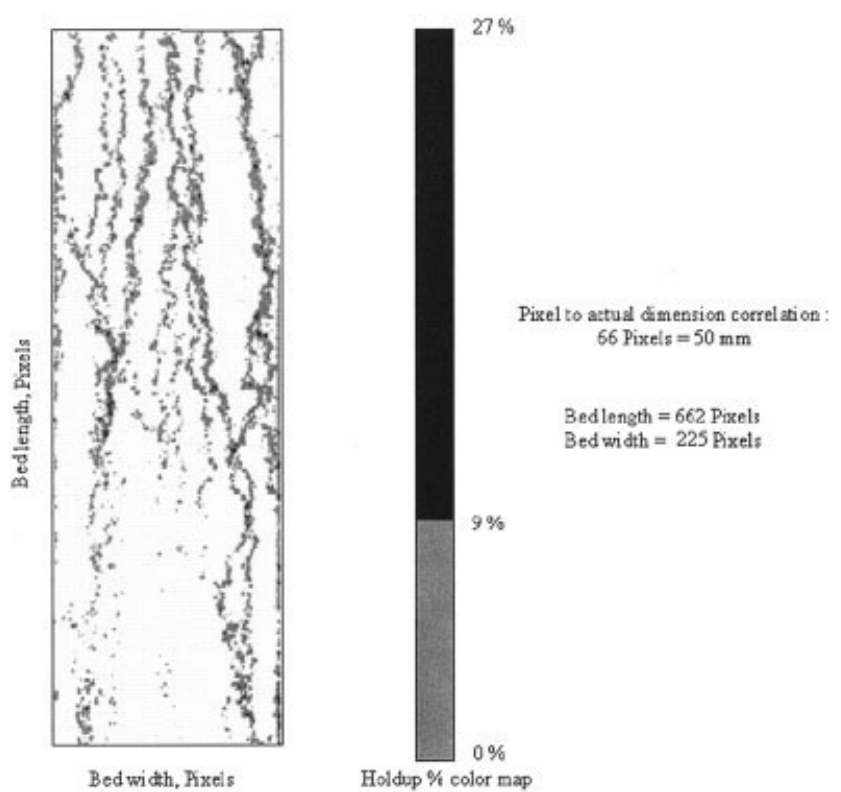

Figure 5. Spatial local dynamic holdup variation in the packed bed domain at $0.175 \mathrm{Ipm}$.

in increasing order without disturbing the bed packing. Once the X-ray scanning was over at $0.08 \mathrm{lpm}$, the flow rate was decreased to $0.06 \mathrm{lpm}$ through each rotameter. The bed was scanned again after reaching the steady state with respect to liquid flow. The same procedure was repeated for other decreasing liquid flow rates (that is, 0.04 and $0.02 \mathrm{lpm}$ ).

The analysis of X-ray images obtained from the abovementioned procedure give total liquid holdup only. To obtain static liquid holdup a separate experiment was performed. In this experiment, first the steady state of liquid flow was achieved at $0.02 \mathrm{lpm}$ and an X-ray image was taken for the whole bed. Flow was stopped to determine the dynamic holdup by collecting the liquid at the bottom for $30 \mathrm{~min}$. Again the bed was scanned with X-ray to determine the static holdup. After that flow was returned again to $0.02 \mathrm{lpm}$ and the apparatus remained in this condition for $15 \mathrm{~min}$. Then the flow rate was increased in steps from 0.02 to $0.08 \mathrm{lpm}$ with an increment of 0.02 , as was done for the hysteresis experiment, and the measuring procedure repeated. At each step $15 \mathrm{~min}$ were given to stabilize the flow in the packed bed. In the same way the liquid flow rate was decreased incrementally to $0.02 \mathrm{lpm}$. At this flow $(0.02 \mathrm{lpm})$, after maintaining the steady state, an X-ray image of the whole bed was taken. Liquid flow rate was stopped and the dynamic liquid holdup from the bed was collected at the bottom of the bed for $30 \mathrm{~min}$. Again the bed was scanned with X-ray.

\section{Processing of Recorded Image}

For the three conditions described in the experimental procedure above, three images — bed image (apparatus + beads) (Figure 4a), flow image (apparatus + beads + flowing liquid) (Figure 4b), and static image (apparatus + beads + static liquid) (Figure 4c)—were obtained. These images have been used to obtain the local static, dynamic, and total (global) estimation of liquid holdups. Figure 4 shows the X-ray images of the packed bed under different experimental conditions. The dark regions in the images $4 \mathrm{~b}$ and $4 \mathrm{c}$ show the presence of aqueous barium chloride tracer. Total holdup was obtained from images $4 \mathrm{a}$ and $4 \mathrm{~b}$, static holdup from the images $4 \mathrm{a}$ and $4 \mathrm{c}$, and the dynamic holdup from the images $4 \mathrm{~b}$ and $4 \mathrm{c}$. A packed bed image without flow (Figure 4a) was used as the base image to detect liquid holdup from the other images, as discussed in the sections on X-ray absorption theory and calibration. The presence of beads cannot be seen in the image of the empty bed (Figure 4a) because the X-ray absorption through them was negligible. Because the liquid flow rates used during the experiments were very low, the flow rate did not affect the bed structure despite the very low density of the beads.

\section{Local holdup}

From the images illustrated in Figure 4, the packed region of the bed was analyzed as follows. Images were read by MATLAB using the IMREAD function, which reads the gray-scale intensity corresponding to the pixels in the images. Thus these images are arrays of the pixels in two dimensions, ranging from $i=1$ to $m$, in the $x$-direction and $j=1$ to $n$ in the $y$-direction for a 2-D Cartesian coordinate system. The intensity arrays may be represented by $I_{B}, I_{F}$, and $I_{S}$, respectively, for the bed, flow, and static images. Equation 8 gives the liquid thickness, $x_{3}=\left(\ln I_{0}-\ln I_{3}\right) / M$ (slope of the calibration curve). With the help of the calibration graph (Figure 1), the percentage of local dynamic holdup $\left[h_{d l}(i, j)\right]$ in a pixel can be expressed as

$\frac{h_{d l}(i, j)=\left\langle\left\{\ln \left[I_{S}(i, j)\right]-\ln \left[I_{F}(i, j)\right]\right\} / M\right\rangle \times 1 \text { pixel } \times 1 \text { pixel }}{(T \times 1 \text { pixel } \times 1 \text { pixel })}$

where $T$ is the thickness of the packed region of the bed. The numerator in the above equation represents the dynamic holdup volume in a pixel at $(i, j)$ under the fluid flow conditions and

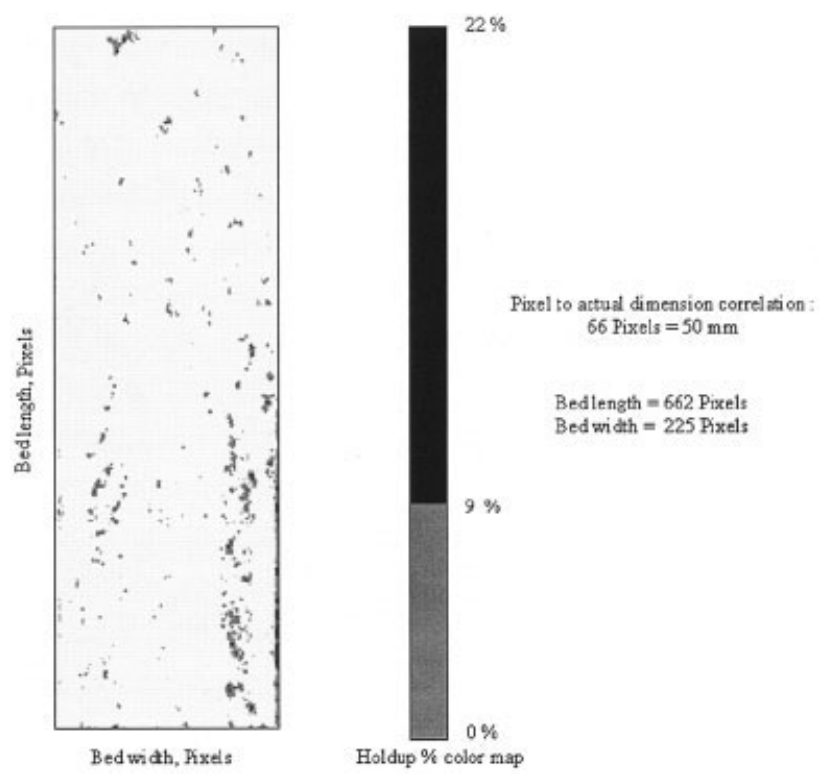

Figure 6. Spatial local static holdup variation in the packed bed domain at $0.175 \mathrm{Ipm}$. 

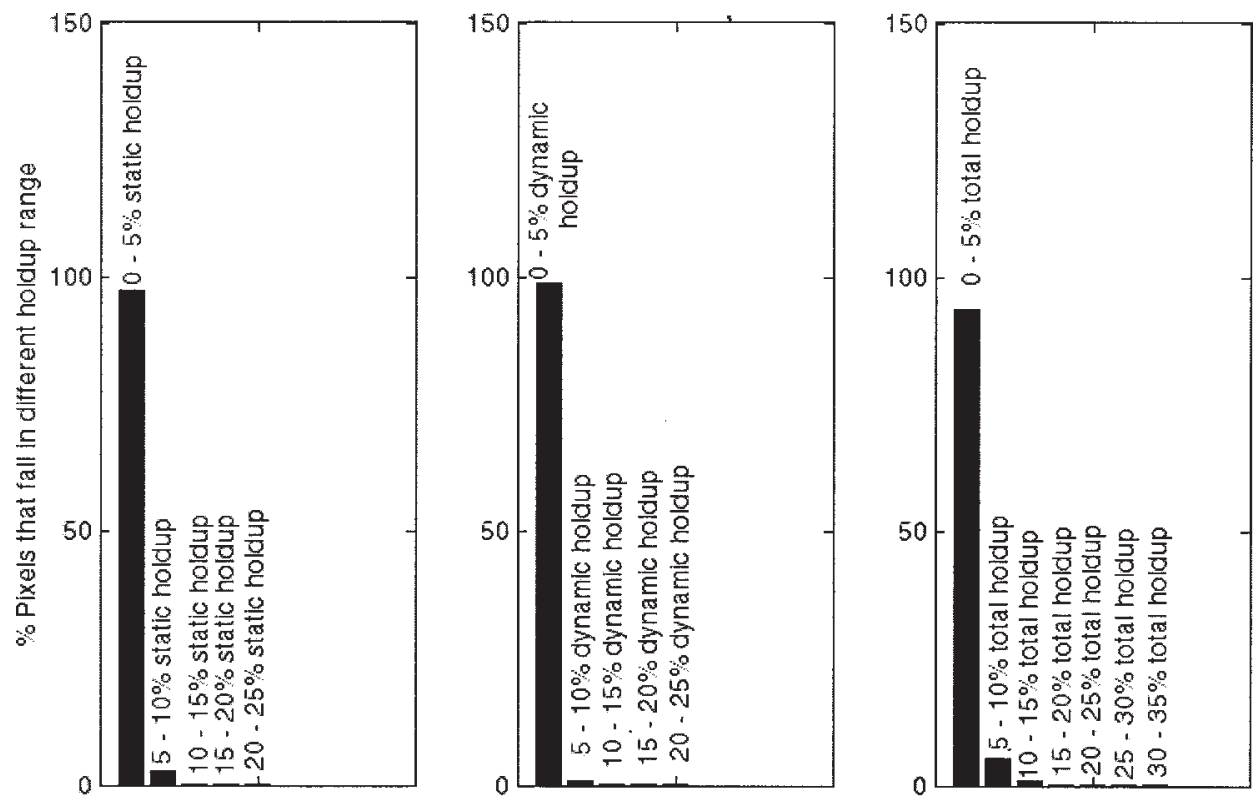

Figure 7. Local liquid holdup distribution in terms of pixels.

denominator represents the corresponding total pixel volume. It can be noted that the local values presented are the values averaged over the bed thickness $(T)$.

Similarly local static $\left(h_{s l}\right)$ and total $\left(h_{t l}\right)$ holdups may be formulated as

$h_{s l}(i, j)=\frac{\left\langle\left\{\ln \left[I_{B}(i, j)\right]-\ln \left[I_{S}(i, j)\right]\right\} / M\right\rangle \times 1 \text { pixel } \times 1 \text { pixel }}{(T \times 1 \text { pixel } \times 1 \text { pixel })}$

$h_{t l}(i, j)=\frac{\left\langle\left\{\ln \left[I_{B}(i, j)\right]-\ln \left[I_{F}(i, j)\right]\right\} / M\right\rangle \times 1 \text { pixel } \times 1 \text { pixel }}{(T \times 1 \text { pixel } \times 1 \text { pixel })}$

Values of the total holdup obtained using Eq. 12 and by the addition of Eqs. 10 and 11 were found to be the same.

\section{Global holdups}

$X$-ray Method. The following method is used to evaluate the global holdup by X-ray technique.

Arrays $I_{B}, I_{F}$, and $I_{S}$ are obtained in similar way as for the local holdup. Natural logarithms of gray values of each pixel in $I_{B}, I_{F}$, and $I_{S}$ images are taken and summed. Thus the global dynamic holdup $h_{d}$ can be given as (in percentage)

$$
h_{d}=\frac{\sum_{i=1}^{i=m} \sum_{j=1}^{j=n}\left\{\ln \left[I_{S}(i, j)\right]-\ln \left[I_{F}(i, j)\right]\right\} \times \frac{1 \text { pixel } \times 1 \text { pixel }}{M}}{[(m) \times 1 \text { pixel }] \times[(n) \times 1 \text { pixel }] \times T}
$$

where $m$ and $n$ are image dimensions in terms of pixels. The numerator of Eq. 13 represents the total dynamic holdup volume in the bed under flowing conditions and the denominator represents the total bed volume.

Similarly, the global static and total holdups can be calculated.

Drainage Method and Tracer Dynamic Technique. The drainage method has been used widely in the literature to determine global dynamic and static liquid holdups, whereas the tracer dynamic technique has been used to determine global total liquid holdup. Details of these methods can be found in relevant studies reported in the literature. ${ }^{4,35-37}$ Both methods have been used in the present study in determining dynamic, static, and total holdups.

\section{Results and Discussion \\ Liquid holdup}

Figures 5 and 6 show the spatial variation of local dynamic and static liquid holdups at $0.175 \mathrm{lpm}$ liquid flow rate. Quali-

\begin{tabular}{|c|c|c|c|c|c|c|}
\hline \multirow[b]{2}{*}{ Experiment } & \multicolumn{3}{|c|}{ Holdup by Drainage Method } & \multicolumn{3}{|c|}{ Holdup by X-ray Absorption } \\
\hline & Static & Dynamic & Total Holdup & Static & Dynamic & Total Holdup \\
\hline I & 1.06 & 1.11 & 2.17 & 1.17 & 0.94 & 2.11 \\
\hline II & 1.33 & 1.19 & 2.52 & 1.32 & 0.81 & 2.13 \\
\hline
\end{tabular}

Table 1. Holdup Data Validation at $0.35 \mathrm{lpm}$ Liquid Flow Rate*

*All holdup values are given in terms of percentage of bed volume. 
Table 2. Percentage Total Liquid Holdup $h_{t}$ at Different Liquid Flow Rates Using Different Techniques

\begin{tabular}{cccc}
\hline \multirow{2}{*}{$\begin{array}{c}\text { Total Liquid Flow } \\
\text { Rate (lpm) }\end{array}$} & \multicolumn{2}{c}{ Percentage Total Liquid Holdup, $h_{t}$} \\
\cline { 2 - 4 } & $\begin{array}{c}\text { Drainage } \\
\text { Technique }\end{array}$ & $\begin{array}{c}\text { Tracer } \\
\text { Response }\end{array}$ & $\begin{array}{c}\text { X-ray } \\
\text { Technique }\end{array}$ \\
\hline 0.175 & 2.01 & 2.10 & 1.82 \\
0.35 & 2.52 & 2.95 & 2.13 \\
0.49 & 3.99 & 3.98 & 3.72 \\
\hline
\end{tabular}

tatively, in terms of intensity, the variation in liquid holdups matches very well with the corresponding X-ray at $0.175 \mathrm{lpm}$ (Figure 4b). Quantitatively, it was found that in some pockets of the packed bed, maximum local static, dynamic, and total holdups were $22.58,27.27$, and $32.02 \%$ of the local pixel volume, respectively. The percentage local liquid holdup is given in terms of local pixel volume because the size of pixel, in physical dimensions $(0.757 \times 0.757 \times$ thickness of apparatus in $\mathrm{mm}$ ), is known. Figure 7 shows a bar diagram to provide a picture of the local variation of different types of liquid holdup (with pixels). Figure 7 shows that majority of the pixels have local holdup between 0 and $5 \%$, but some pixels are higher, from 5 to $27 \%$. These high liquid holdups in a packed bed reactor application may contribute significantly toward the heat and mass transfer. This technique clearly demonstrates localized flooding in packed beds.

Similar results were found for the other liquid flow rates (that is, at 0.35 and $0.49 \mathrm{lpm}$ ).

\section{Validation of technique}

Global liquid holdup results, obtained by the X-ray technique, have been compared with the results obtained by two conventional methods: drainage (dynamic and static holdup) and tracer response (total holdup). Because the conventional techniques can give only global liquid holdups, local liquid holdups cannot be compared. Table 1 shows a comparison of global static, dynamic, and total holdups, obtained by X-ray and drainage techniques at $0.35 \mathrm{lpm}$ liquid flow rate. There is some discrepancy between the replicate experiments, but this may be expected because of stochastic differences in the packing between experiments.

Table 2 shows a comparison between the total liquid holdup obtained by all three methods. The methods give broadly

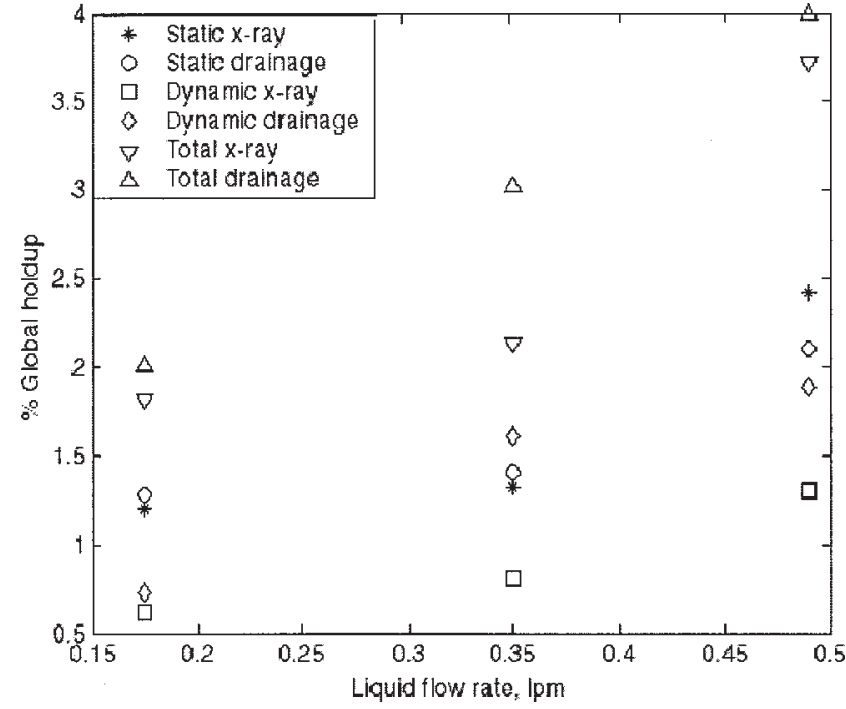

Figure 8. Global liquid holdup by X-ray and drainage methods.

similar results, although there are some systematic discrepancies, which are discussed below.

The conventional methods always give slightly higher values for all types of liquid holdups (Table 1, Table 2, and the bottom two rows of Table 3). This is also apparent in Figure 8, which shows holdups obtained by both the drainage method and $\mathrm{X}$-ray at various liquid flow rates.

The drainage technique involves cutting off the liquid supply to the bed, and a simultaneous start of liquid collection at the bottom of the bed. Even a small time mismatch between these two events may lead to significantly incorrect results. Added tracers present in the outlet tubes, tracer losses arising from dilution (which is done to decrease the concentration limit for analysis by different techniques), and tracer lost during estimation constitute a few of the major drawbacks of the drainage technique. The tracer introduced in the tracer dynamics technique may not have access to all the fluid in the packed bed, which would again lead to wrong holdup estimation. Residence time of the tracer estimated may be more or less the result of stagnation and channeling effects. All these factors may contribute toward inaccuracy in measuring the static and dynamic liquid holdups.3,10 On the other hand, the X-ray

Table 3. Local Liquid Holdup Data Obtained from the Analysis of Figure 12*

\begin{tabular}{|c|c|c|c|c|}
\hline $\begin{array}{c}\text { Part of the Bed (see } \\
\text { Figure 12) }\end{array}$ & $\begin{array}{l}\text { Inc. Dynamic } \\
\text { Total Holdup } \\
\quad(\text { vol \%) }\end{array}$ & $\begin{array}{c}\text { Inc. Static } \\
\text { Total Holdup } \\
\quad(\text { vol \%) }\end{array}$ & $\begin{array}{c}\text { Dec. Dynamic } \\
\text { Total Holdup } \\
(\text { vol \%) }\end{array}$ & $\begin{array}{l}\text { Dec. Static } \\
\text { Total Holdup } \\
\quad(\text { vol \%) }\end{array}$ \\
\hline 1 & 0.80 & 0.71 & 1.31 & 1.13 \\
\hline 2 & 0.73 & 0.64 & 1.37 & 1.19 \\
\hline 3 & 0.59 & 0.55 & 0.99 & 1.24 \\
\hline 4 & 0.57 & 0.62 & 1.03 & 1.39 \\
\hline 5 & 0.39 & 0.38 & 0.95 & 1.11 \\
\hline 6 & 0.55 & 0.52 & 0.97 & 1.32 \\
\hline 7 & 0.33 & 0.49 & 1.06 & 1.18 \\
\hline 8 & 0.49 & 0.64 & 0.88 & 1.36 \\
\hline Average & 0.56 & 0.58 & 1.07 & 1.24 \\
\hline \multicolumn{5}{|l|}{ Average } \\
\hline (drainage method) & 0.59 & & 1.18 & \\
\hline
\end{tabular}

*Inc., increasing; Dec., decreasing. 

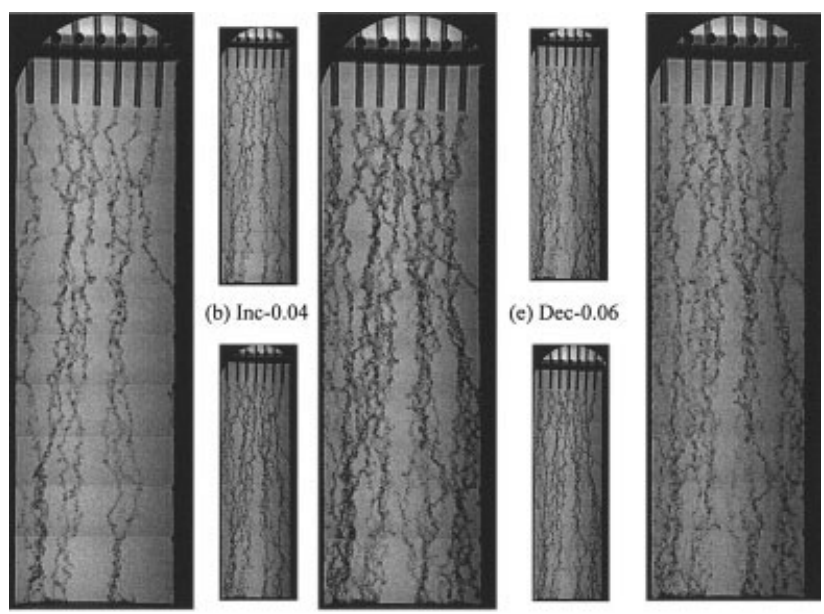

(a) Inc-0.02 Ipm

(c) Inc-0.06

(d) Inc-0.08

(f) Dec-0.04

(g) Dec-0.02

Figure 9. X-ray images of the bed at different liquid flow rates (Inc, increasing; Dec, decreasing).

technique may be expected to give more accurate results because most of the conventional techniques errors are not present here. In the X-ray method, in particular, one can consider only that region of the bed that is packed, whereas this is not possible to do in conventional methods. This means conventional methods will always give higher values of liquid holdups than those obtained by the X-ray method.

Clearly the X-ray method is capable of giving all types of liquid holdups in a packed bed quantitatively and more accurately than those obtained by conventional methods if it is carefully done. There are many precautions that require attention during the X-ray experiments. The major errors associated with X-ray technique are described below in brief.

\section{Errors associated with X-ray method}

For the purpose of quantification care is necessary to minimize the errors that may be associated with either the experiments or the X-ray unit.

The position of the object between the detector and X-ray source is an important parameter because it affects the image size and thus the intensity. Similarly, point source emission of $\mathrm{X}$-ray introduces significant errors in the results if the distance between the detector and source is large. This may be reduced by scanning a small area at a time using collimators. It can be eliminated if X-ray beams are parallel. In the present study its maximum contribution is $<1 \%$.

It is important to have a minimum number of image-processing operations in quantifying the results because these operations invariably introduce errors that can range from negligible to very significant. ${ }^{15,16}$ Another potential error is introduced through beam hardening that, as discussed earlier, can be reduced in various ways. Maintaining equivalent conditions during calibration and experiment, and keeping to low tracer concentration are necessary to minimize the errors.

\section{Liquid hysteresis}

Figure 9 shows the X-ray images of the bed at various increasing liquid flow rates (images 9 a to $9 \mathrm{~d}$ ) and decreasing liquid flow rates (images $9 \mathrm{e}$ to $9 \mathrm{~g}$ ). The figures show how the flow lines/rivulets develop in both the transverse and longitudinal directions as the liquid flow rate is increased. On a nonwetting packing, liquid flow can occur either in the form of rivulets, film flow, or droplets or in combination of any of these flows, depending on the liquid flow rate. Coalescence and breaking of rivulets/droplets occur while they are meandering down the packing. Near the liquid feeding points, the liquid flows as rivulets/droplets, which are continuously breaking up and reforming. The number of channels increases a slight distance away from the top portion of the bed where the liquid is fed into the bed, then remaining more or less constant as liquid travels down to the bottom of the bed. In some places, particularly near the bottom of the bed, coalescence of rivulets occurs thus reducing their numbers, which leads to an increase in their size (or volume) (see Figure 9a). As the size/volume of rivulets/droplets increases the intensity of that portion of the bed diminishes (that is, it becomes darker). One can clearly see darker regions toward the bottom of the bed in Figure 9a. As such, dynamic holdup has dispersed more (high intensity, less dark) at the top of the bed and it has narrowed down near the bottom of the bed (less intensity, darker regions). There is some spreading and stochastic behavior and the liquid occupies a relatively small fraction of the total void space. On increasing the flow rate, rivulets grow both in size/volume and numbers, given that they can be clearly seen in these images (Figures 9a to $9 \mathrm{~d})$. This is contrary to what has been reported earlier. ${ }^{20}$ This large spatial nonuniformity in holdup indicates, in mathematical modeling, that liquid flow should be treated as a discrete flow supporting modeling methods using this basis. ${ }^{1,38}$ When packing is highly nonwetting, the flow of liquid is dominated by rivulets/droplets rather than film formation.

As the liquid flow rate is increased, rivulets increase in size and begin to split in the top portion of the bed (that is, near the feeding point of liquid). This contributes toward an increase in both static and dynamic holdups. However, as the fluid flow rate is decreased from maximum this spreading is maintained rather than reverting back to a smaller number of channels, consistent with the same flow in increasing case (see images 9a

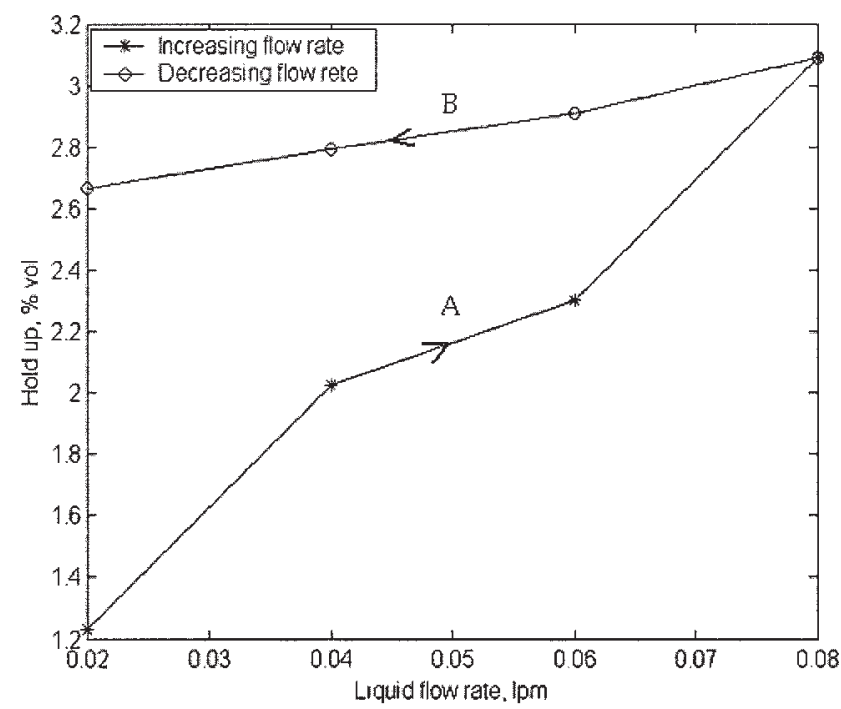

Figure 10. Experimental liquid hysteresis. 

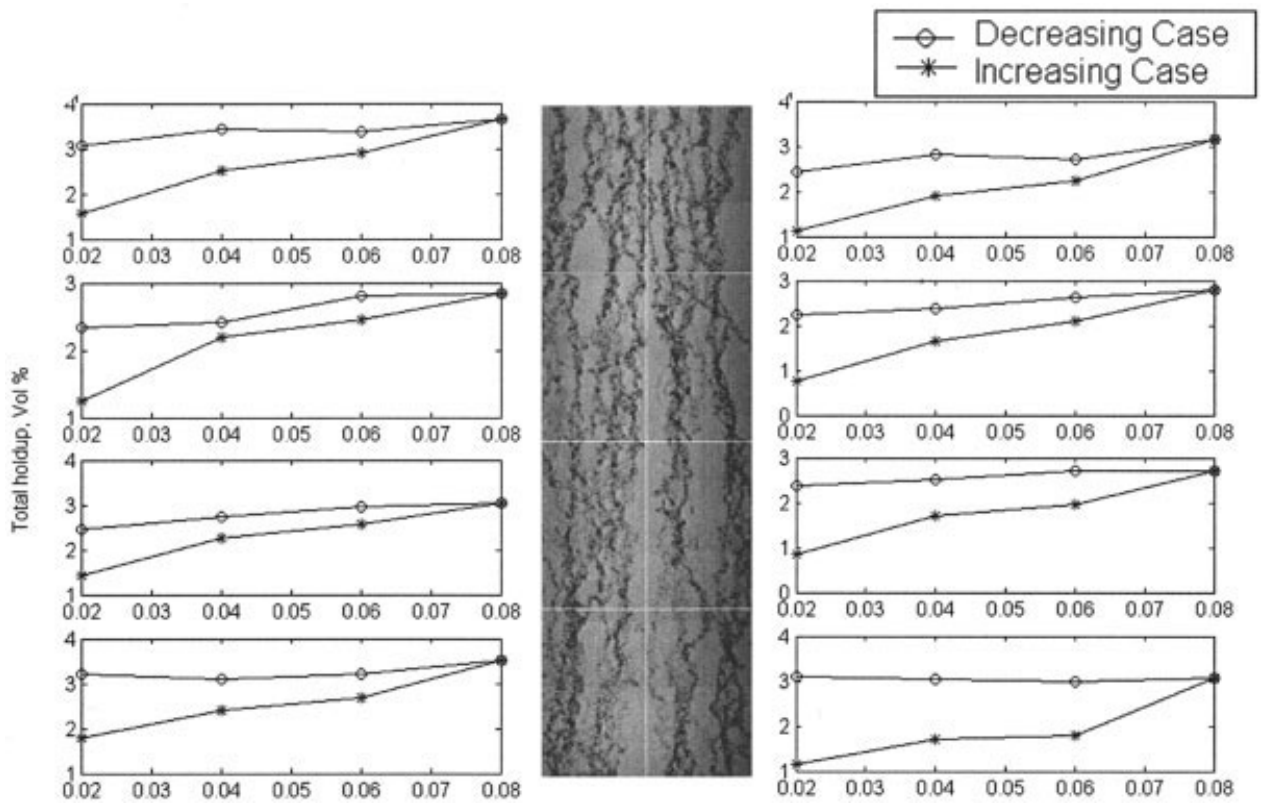

Figure 11. Local liquid hysteresis loops in various parts of the bed.

and $9 \mathrm{~g}$ ). As the liquid flow rate continues to decrease, supply of the liquid to rivulets is reduced, causing them to flow like thin film or droplets. In another way rivulets become porous as explained by other researchers. ${ }^{20}$ It is evident from these figures that as the flow decreases, rivulets maintain continuity in structure, although the volume of liquid inside them has been reduced. If the flow is further reduced a point is reached when the rivulets break and become discontinuous, there is an insufficient liquid supply to maintain them either in rivulet or film flow form (images $9 \mathrm{~d}$ to $9 \mathrm{~g}$ ).

In Figure 10 the total liquid holdup is plotted against the liquid flow rate showing the liquid hysteresis curve. Curve $\mathrm{A}$ is for increasing flow and curve B is for decreasing flow rate. From this plot it is apparent that the holdup in the decreasing case is always greater than the holdup in the increasing case at a particular liquid flow rate. These results are in accordance with the observation made by Levec et al.,22 but are contrary to those reported by Christensen et al. ${ }^{20}$ The most probable reason is that the microwave technique used by Christensen et al. was not accurate enough to give the correct quantitative results. Reasons for the increase in liquid holdup at a decreasing flow rate are clear from images $9 \mathrm{a}(0.02 \mathrm{lpm}$, increasing flow rate) and $9 \mathrm{~g}(0.02 \mathrm{lpm}$, decreasing liquid flow rate) in Figure 9. The number of rivulets in the decreasing flow rate scenario are higher in both transverse and longitudinal directions. This leads to more dynamic and static liquid holdups resulting from increases in the liquid-solid surface area and contact zones besides the other factors discussed earlier.

To characterize the local hysteresis loops in the various regions of the bed at each liquid flow rate in increasing and decreasing conditions, the bed was divided into eight parts and corresponding hysteresis loops are shown in Figure 11. The bed image in Figure 11 is at $0.08 \mathrm{lpm}$ flow rate. It may be noted that, although the nature of hysteresis holdup pattern is identical for all the regions considered for analysis, the gap between the total holdups in different regions of the bed is not the same. For example, in bed regions 1 and 2 the total holdup is about
1.5 and $1 \%$ (for the increasing case), respectively. In the decreasing case it is about 3 and $2.5 \%$, respectively. This can be attributed to the stochastic nature of the bed packing and also to the irregularities in the flow distribution. On a qualitative basis the holdups match very well with their respective images in the bed.

Figure 12 shows the $\mathrm{X}$-ray images of increasing and decreasing liquid flow rates at $0.02 \mathrm{lpm}$. To analyze the local static and dynamic liquid holdups quantitatively, images were divided into eight parts, as was done in Figure 11. The results obtained are provided in Table 3.
Inc - Total

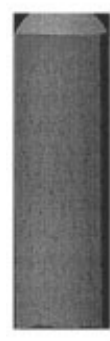

Dec-Static Division of bed

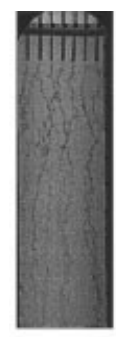

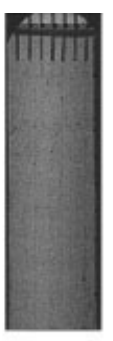

Inc - Static

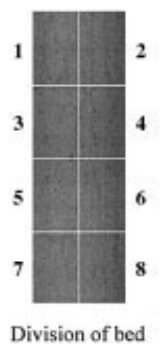

Figure 12. Liquid hysteresis X-ray images used to determine static and dynamic holdups quantitatively at $0.02 \mathrm{lpm}$ liquid flow rate.

Data are given in Table 3. 
Table 3 provides a number of important insights. For example, for increasing flow both the static and dynamic holdups are higher near the top of the bed. Lower down both the holdups are decreased. This is in agreement qualitatively with the X-ray image in Figure 12. This figure shows that most flowlines/ rivulets are observed in the top portion of the bed compared to the lower portion, resulting in an increase in the liquid-solid contact area in the top portion. The liquid spends more time in zone 1 than in zone 7 because of the more tortuous path it follows in zone 1 . The result is higher static and dynamic holdups in zone 1 of the bed. An alternate description is that greater dispersion occurs in the top portion of the bed. Table 3 shows that for the decreasing flow both the static and dynamic holdup values have increased, although they are much less prominent than for the increasing flow rate. One of the reasons is that the number of rivulets is maintained in the decreasing flow rate (see Figure 12), which means the time spent by the liquid in each portion of the bed is roughly the same. As flow is reduced the bed retains most of the hydrodynamic and structural properties that were present at higher liquid flow rates. By contrast, for the increasing flow rate, the channel structure of the bed is being evolved. This demonstrates that bed history is very important in determining the liquid holdup, as has also been indicated by other researchers. ${ }^{22,24}$ Total holdup comes from the sum of both the static and dynamic holdups for both increasing and decreasing liquid flow rates.

\section{Conclusions}

An elegant calibration technique has been presented to quantify the local liquid holdup values in porous media. The technique uses a polychromatic X-ray source and low concentration of tracer to avoid beam hardening. Only one image processing operation is needed to process the images, obtained by X-ray imaging. Comparison of global liquid holdups results achieved using other conventional methods-drainage and tracer response-shows that the X-ray method may give better results.

This visualization/calibration technique has been used to study quantitatively the liquid hysteresis phenomena in a packed bed. It has been shown that as the liquid flow rate increases the formation of rivulets/droplets is increased both in size and numbers. However, when flow is reduced, the number of rivulets and the channels in which they flow are retained. Consequently, bed history plays an important role. Both static and dynamic liquid holdups contribute toward the hysteresis phenomena. The bed hysteresis phenomena have been demonstrated even at the local level within the packed bed and this has important consequences for the correct modeling of such systems.

\section{Acknowledgments}

The work was supported financially by the Council of Scientific and Industrial Research (CSIR), India by Grant 22(0361)/02/EMR-II. X-ray equipment was bought under the grant provided by Ministry of Steel. One of the authors (R.B.) thanks Jawaharlal Nehru Centre for Advanced Scientific Research, Bangalore, for providing the Summer Research Fellowship.

\section{Literature Cited}

1. Gupta GS, Litster JD, Rudolph VR, White ET, Domanti A. Model studies of liquid flow in the blast furnace lower zone. ISIJ Int. 1996; 36:32-39.
2. Gupta GS, Litster JD, Rudolph VR, White ET. Nonwetting flow of a liquid through a packed bed with gas cross-flow. Metall Trans. 1997; 28B:597-604.

3. Schubert CN, Lindner JR, Kelly RM. Experimental methods for static holdup in packed columns. AIChE J. 1985;32:1920-1923.

4. Inglezakis VJ, Lemonidou M, Grigoropoulou HP. Liquid holdup and flow dispersion in zeolite packed beds. Chem Eng Sci. 2001;56:50495057.

5. Mao ZS, Xiong TY, Chen J. Theoretical prediction of static liquid holdup in trickle bed reactor and comparison with experiments results. Chem Eng Sci. 1993;48:2697-2703.

6. Shulman HL, Ullrich CF, Wells N. Performance of packed columns: Part I. Total, static, and operating holdups. AIChE J. 1955;1:247-253.

7. Charpentier JC, Prost C, Van Swaaij WPM, Le Geoff P. Étude de la rétention de liquide dans une colonne à garnissage arrosé à co-courant et à contre-courant de gaz-liquide. Représentation de sa texture par un modèle à filets et gouttes. Chim Ind Gén Chim. 1968;99:803.

8. Van Swaaij WPM, Charpentier JC, Villermaux J. Residence time distribution in the liquid phase at trickle flow in packed columns. Chem Eng Sci. 1969;24:1083-1095.

9. Charpentier JC, Prost C, Le Geoff P. Pressure drop in trickle flow compared to bubble flow for two-phase co-current gas-liquid in packed beds. Chem Eng Sci. 1969;24:1777-1794.

10. Fuhe Y, Artin A, Nandakumar K, Chuang KT. Liquid holdup distribution in packed columns: Gamma ray tomography and CFD simulations. Chem Eng Process. 2002;41:473-483.

11. Jasti JK, Foglar HS. Application of neutron radiography to image flow phenomena in porous media. AIChE J. 1992;38:481-488.

12. Lutran PG, Na KN. Liquid distribution in trickle beds. An experimental study using computer-assisted tomography. Ind Eng Chem Res. 1991;30:1270-1280.

13. Gupta GS, Litster JD, Rudolph VR, White ET. Flow visualization study in porous media using X-rays. Steel Res. 1997;68:434-440.

14. Toye D, Marchot P, Crine M, Pelsser AM, L'Homme G. Local measurement of void fraction and liquid holdup in packed columns using X-ray computed tomography. Chem Eng Process. 1998;37:511520.

15. Seymour JD, Callaghan PT. Generalized approach to NMR analysis of flow and dispersion in porous media. AIChE J. 1997;43:2096-2111.

16. Hwa CS, Beckmann RB. Radiological study of liquid holdup and flow distribution in packed gas-absorption columns. AIChE J. 1960;6:359364.

17. Tidwell VC, Glass RJ. X-ray and visible light transmission for laboratory measurement of two-dimensional saturation fields in thin-slab systems. Water Resour Res. 1994;30:2873-2882.

18. Tidwell VC, Meigs LC, Tracy CF, Boney CM. Effects of spatially heterogeneous porosity on matrix diffusion as investigated by $\mathrm{X}$-ray absorption imaging. J Contam Hydrol. 2000;42:285-302.

19. Kan KM, Greenfield PF. Multiple hydrodynamics states in cocurrent two-phase downflow through packed beds. Ind Eng Chem Proc Des Dev. 1978; 17:482-485.

20. Christensen G, McGovern SJ, Sundaresan S. Cocurrent downflow of air and water in a two-dimensional packed column. AIChE J. 1986; $32: 1677-1689$

21. Saez AE, Carbonell RG, Levec J. The hydrodynamics of trickling flow in packed beds: Part I. Conduit models. AIChE J. 1986;32:353-368.

22. Levec J, Saez AE, Carbonell RG. The hydrodynamics of trickling flow in packed beds: Part II. Experimental observations. AIChE J. 1986; 32:369-380.

23. Levec J, Grosser K, Carbonell RG. The hysteresis behaviour of pressure drop and liquid holdup in trickle beds. AIChE J. 1988;34:10271030.

24. Gupta GS, Bhattacharyya S. Liquid holdup in non-wetting packing with lateral gas injection. ISIJ Int. 2003;43:1927-1935.

25. Aza'roff LV. Elements of X-ray Crystallography. New York, NY: McGraw-Hill; 1968.

26. Cullity BD. Elements of X-ray Diffraction. Reading, MA: AddisonWesley; 1956.

27. Clark CJ. The Encyclopedia of X-rays and Gamma Rays. New York, NY: Reinhold Publishing; 1963.

28. Kleinschmidt C. Analytical considerations of beam hardening in medical accelerator photon spectra. Med Phys. 1999;26:1995-1999.

29. Ruth C, Joseph PM. A comparison of beam-hardening artifacts in 
X-ray computerized tomography with gadolinium and iodine contrast agents. Med Phys. 1995;22:1977-1982.

30. Goodsitt MM. Beam hardening errors in post-processing dual energy quantitative computed tomography. Med Phys. 1995;22:1039-1047.

31. Alvarez RE, Macovski A. Energy selective reconstructions in X-ray computerized tomography. Phys Med Biol. 1976;21:733-744.

32. Hammersberg P, Mangard M. Correction for beam hardening artifacts in computerized tomography. J X-ray Sci Technol. 1998;8:75-93.

33. Geet VM, Swennen R, Wevers M. Quantitative analysis of reservoir rocks by microfocus X-ray computerized tomography. Sediment Geol. 2000;132:25-36.

34. Basavaraj MG. Determination of Local Dispersion Coefficient and Local Holdup in a Packed Bed Using X-rays. MS Thesis. Bangalore, India: Indian Institute of Science; 2002.
35. Gupta GS, Litster JD, Rudolph VR, White ET. Liquid distribution at the bottom of the blast furnace. CRL Rep. No. 67/03. Newcastle, Australia: BHP Steel; 1993.

36. Levenspiel O. The Chemical Reactor Omnibook. Corvallis, OR: Oregon State Univ. Press; 1979.

37. Levenspiel O. Chemical Reaction Engineering. New York, NY: Wiley; 1999.

38. Wang GX, Liu DY, Litster JD, Yu AB, Chew SJ, Zulli P. Experimental and numerical simulation of discrete liquid flow in a packed bed. Chem Eng Sci. 1997;52:4013-4019. 